\title{
Effects of losartan and atorvastatin on the
} \section{development of early posttraumatic joint stiffness in a rat model}

This article was published in the following Dove Press journal:

Drug Design, Development and Therapy

\author{
Andreas Baranowski (D) \\ Ludwig Schlemmer' \\ Katharina Förster ${ }^{\prime}$ \\ Ekaterina Slotina' \\ Tim Mickan' \\ Sebastian Truffel' \\ Anja Klein' \\ Stefan G Mattyasovszky' \\ Alexander Hofmann ${ }^{1,2}$ \\ Ulrike Ritz' \\ Pol M Rommens' \\ 'Department of Orthopaedics and \\ Traumatology, Biomatics Group, \\ University Medical Centre of the \\ Johannes Gutenberg University, Mainz, \\ Germany; ${ }^{2}$ Department of Traumatology \\ and Orthopaedics I, Westpfalz-Medical \\ Centre Kaiserslautern, Kaiserslautern, \\ Germany
}

Background: After a trauma, exuberant tissue healing with fibrosis of the joint capsule can lead to posttraumatic joint stiffness (PTJS). Losartan and atorvastatin have both shown their antifibrotic effects in different organ systems.

Objective: The purpose of this study was the evaluation of the influence of losartan and atorvastatin on the early development of joint contracture. In addition to joint angles, the change in myofibroblast numbers and the distribution of bone sialoprotein (BSP) were assessed.

Study design and methods: In this randomized and blinded experimental study with 24 rats, losartan and atorvastatin were compared to a placebo. After an initial joint injury, rat knees were immobilized with a Kirschner wire. Rats received either losartan, atorvastatin or a placebo orally daily. After 14 days, joint angle measurements and histological assessments were performed.

Results: Losartan increased the length of the inferior joint capsule. Joint angle and other capsule length measurements did not reveal significant differences between both drugs and the placebo. At cellular level both losartan and atorvastatin reduced the total number of myofibroblasts (losartan: $191 \pm 77$, atorvastatin: $98 \pm 58$, placebo: $319 \pm 113$ per counting field, $p<0.01$ ) and the percentage area of myofibroblasts (losartan: $2.8 \pm 1.8 \%[p<0.05]$, atorvastatin: $2.5 \pm 1.7 \%[p<0.01]$, vs control [6.4 $\pm 4 \%]$, respectively). BSP was detectable in equivalent amounts in the joint capsules of all groups with only a trend toward a reduction of the BSPstained area by atorvastatin.

Conclusion: Both atorvastatin and losartan reduced the number of myofibroblasts in the posterior knee joint capsule of rat knees 2 weeks after trauma and losartan increased the length of the inferior joint capsule. However, these changes at the cellular level did not translate an increase in range of motion of the rats' knee joints during early contracture development.

Keywords: posttraumatic joint stiffness, knee joint contracture, rat model, myofibroblast, antifibrotic drugs, bone sialoprotein

\section{Introduction}

In case of joint dislocation or joint-related fractures, tissue integrity is compromised and mechanisms for the rapid restoration of mechanical stability are initiated. $^{1-3}$ Exuberant tissue healing can lead to posttraumatic joint stiffness (PTJS) and a reduced quality of life of those affected. PTJS is a fibrotic joint disorder that can occur in most joints after injury or trauma. It is characterized by excessive extracellular matrix (ECM) production and synovial adhesions that
Correspondence: Andreas Baranowski Department of Orthopaedics and Traumatology, University Medical Center Mainz, Langenbeckstraße I, Mainz 55I3I, Germany

$\mathrm{Tel}+49613 \quad 1177292$

Fax $+49613 \quad 1174043$

Email andreas.baranowski@unimedizinmainz.de 
result in restricted joint motion. Synonyms for this disorder are joint contracture, stiff knee, stiff elbow or arthrofibrosis. $^{4,5}$ In our study, PTJS of the knee was defined as a limited passive extension of the knee joint after trauma, which was not caused by incongruency of the joint. Prolonged physiotherapeutic treatment or operative removal of the joint capsule (with certain associated risks) are often capable of improving the range of motion in PTJS. Still, there is no medical prophylaxis or treatment for this crippling condition. It has been shown that joint contracture is associated with an increased number of myoblastic differentiated fibroblasts, the socalled myofibroblasts. ${ }^{3,6}$ Myofibroblasts are fibroblastlike cells that form intracellular stress fiber microfilament bundles. These bundles express contractile proteins, such as alpha-smooth muscle actin ( $\alpha$-SMA), and allow the cells to have a high contractile activity. ${ }^{1,7}$ In addition, myofibroblasts develop integrins and large focal adhesions to link the cytoskeleton to the ECM. ${ }^{8}$ In this way, cell forces can be transmitted to the ECM and, vice versa, extracellular mechanical stress can be sensed by the myofibroblast. The mechanical load of the ECM is partially generated by the myofibroblasts and leads to a positive feedback, which, together with stimulation by TGF- $\beta 1$, results in their persistent activity. Persistent myofibroblasts were found in posttraumatic joint contractures or pathological scar tissue. Since they are known to synthesize large amounts of ECM, fibrogenic mediators and protease inhibitors, the myofibroblast is thought to be a paramount effector cell in many fibrotic diseases. 9 Besides the increase of ECM production and the formation of synovial adhesions, heterotopic ossifications (HOs) are often formed in PTJS. ${ }^{10,11}$ Bosse et al proved the presence of bone sialoprotein (BSP) in HOs and in the activity centers of early osteogenetic areas with accumulation in fibroblasts and preosteoblasts. ${ }^{12}$ Hegyi et al could confirm the presence of BSP in stromal cells and endothelial cells of fibroproliferative lesions in patients with fibrodysplasia ossificans progressiva. ${ }^{13}$ Within these fibroproliferative lesions, which are known to progress to form HO, many stromal cells expressed $\alpha$-SMA as well. In a rat model of ectopic bone formation in a muscle pouch of the thigh, we could show that BSP is capable of inducing HO (unpublished data). BSP can usually be found in subchondral bone, but its serum and joint fluid levels are increased after knee injury. ${ }^{14,15}$ Its role and distribution in the development of PTJS remain unclear. Our hypothesis is that the early expression of BSP in the posttraumatic joint capsule could lead to the later formation of $\mathrm{HO}$ and that the reduction of early BSP expression might attenuate their development.

Apart from their occurrence in posttraumatic joint contractures, myofibroblasts are also a characteristic for fibrosis of organs such as liver, heart, lung or kidney. Significant progress has been made in recent years in the study of the regulatory mechanisms of myofibroblast activation. From these findings, new approaches to treat fibrotic diseases of various organ systems have been developed. To date, antibodies against TGF- $\beta 1$ or the $\alpha 2$ chain of collagen I have been tested in rabbit models of posttraumatic joint contracture, which successfully led to the reduction of postoperative joint contracture. ${ }^{16,17}$ However, the low half-life of the antibodies necessitated continuous intra articular administration by pumping. Similarly, in a rabbit model, mast cell inhibition via decreased release of profibrotic growth factors (basic fibroblast growth factor, platelet-derived growth factor, nerve growth factor and TGF-ß1) resulted in decreased postoperative joint contracture. ${ }^{18}$ In a rat model of postoperative contracture, it was shown that intra articular administration of special interfering RNA molecules successfully disrupted a profibrotic signaling cascade, leading to decreased contracture. ${ }^{19}$

Numerous in vitro studies have shown that inhibition of profibrotic factors or their signaling cascades can inhibit the proliferation and differentiation of myofibroblasts. ${ }^{9,20-22}$ In recent in vitro studies, the drugs losartan, an angiotensin receptor antagonist, and atorvastatin, an inhibitor of HMGCoA reductase, proved to be able to inhibit myofibroblast differentiation. $^{23,24}$ Klein et al showed that atorvastatin concentration-dependently lowered the mRNA levels of profibrotic cytokines (TGF- $\beta 1$ and connective tissue growth factor $[\mathrm{CTGF}]) .{ }^{24}$ In a rat model of liver fibrosis, Trebicka et al demonstrated that early atorvastatin administration not only retards activation of myofibroblasts and reduces subsequent collagen deposition, but also reduces the proliferation rate of myofibroblasts in fibrosis. ${ }^{25}$ The anti fibrotic effect of atorvastatin could also be demonstrated for fibrotic remodeling of the heart or for fibrotic remodeling of the lung. $^{26,27}$ TGF- $\beta 1$ is more extensively expressed in tissue injury, but is also stimulated by the oligopeptide hormone angiotensin II through the angiotensin type 1 (AT-1) receptor in fibroblasts. ${ }^{28,29}$ AT-1 receptor antagonists, such as losartan, can abolish this stimulation and have been effective in reducing fibrosis on various organ systems. ${ }^{30-34}$ It was shown that the blockade of AT-1 receptors by losartan 
reduced the fibrosis in skeletal muscle. ${ }^{35-37}$ However, the applicability of these results to fibrosis in PTJS remains unclear. In a former study, we successfully established a reproducible model of PTJS in rats. ${ }^{38}$ First, we used a hyperextension of $-45^{\circ}$ of the knee joint in order to disrupt the posterior joint capsule. Second, a 2-mm-thick and 4mm-deep hole was drilled into the non cartilaginous part of the lateral femoral condyle to create a standardized intraarticular bony lesion and a hemarthros. Finally, the knee joint was fixed in a knee flexion angle of $145^{\circ}$ for 4 weeks. The reliability of this model and the easy handling of rats render it particularly suitable for the evaluation of medical treatment options. To clarify the anti fibrotic effects of losartan and atorvastatin on the joint capsule, we undertook an in vivo study in our aforementioned rat model. Our objective was to determine if the daily oral administration of atorvastatin or losartan was associated with a reduced number of myofibroblast and a reduction in joint contracture development after 2 weeks. The primary efficacy endpoint was the reduction of joint contracture. Secondary endpoints were differences in cell numbers and changes in the morphology of the posterior joint capsule. Our hypothesis was that atorvastatin and losartan reduce posttraumatic joint contracture via reduction of myofibroblast numbers in the posterior joint capsule in rats. This might lead to a prophylactic treatment of posttraumatic and postoperative joint stiffness in orthopedic and trauma surgery.

\section{Methods}

\section{Study design}

24 male Sprague Dawley rats (Janvier Labs, SaintBerthevin Cedex, France) with a mean weight of $391 \pm 15$ $\mathrm{g}$ and an age of 10 weeks were used for this in vivo study. All animals were kept individually in Makrolon type IV cages (Zoonlab, Castrop-Rauxel, Germany) at room temperature in a 12-hr light/dark cycle. Experimental setup was planned with the Experimental Design Assistant (https:// eda.nc3rs.org.uk/). The rats were randomized with RandList (V 1.2, http://randomisation.eu/) into three equal groups $(\mathrm{n}=8)$, two drug groups and a placebo control group. The number of animals was based on sample size calculations based on our previous study. ${ }^{38}$ Animal caretakers and operating surgeons were blinded and not informed whether a drug or a placebo was administered. Medications were grounded in mortars and mixed with white chocolate spread, which was offered to the animals. The animals gave the treat priority over the regular chow and consumed it immediately and completely. All animals underwent the same surgical procedure and differed in the administered drug only (losartan [30 mg/kg/day orally], atorvastatin [15 $\mathrm{mg} / \mathrm{kg} /$ day orally] and control [placebo]), which was given once daily for 14 days from operation day till euthanasia. The doses of the drugs were selected based on previous small animal models. ${ }^{39-44}$ This study was approved by the local ethics committee (ID 23 177-07/G 13-1-043).

\section{Injury model and surgical procedure}

Standardized capsular and bony knee injuries were surgically created to imitate injury patterns seen in human joint injuries that can lead to PTJS, as described previously. ${ }^{38}$ In brief, after measurement of the initial range of motion of the joint, the left knee of the anesthetized rats was hyperextended to $-45^{\circ}$ in order to disrupt the posterior joint capsule. After surgical prepping, the animals were operated on the left limb under sterile conditions. A 2-mm-thick and 4-mm-deep hole was drilled into the non cartilaginous portion of the lateral femoral condyle (without lateral collateral ligament damage). After that, the knee joint was retained in a $145^{\circ}$ flexed position with a K-wire (Kirschner wire), which was driven through tibia and femur and bent around the bones (Figure 1). Accidental fractures were ruled out

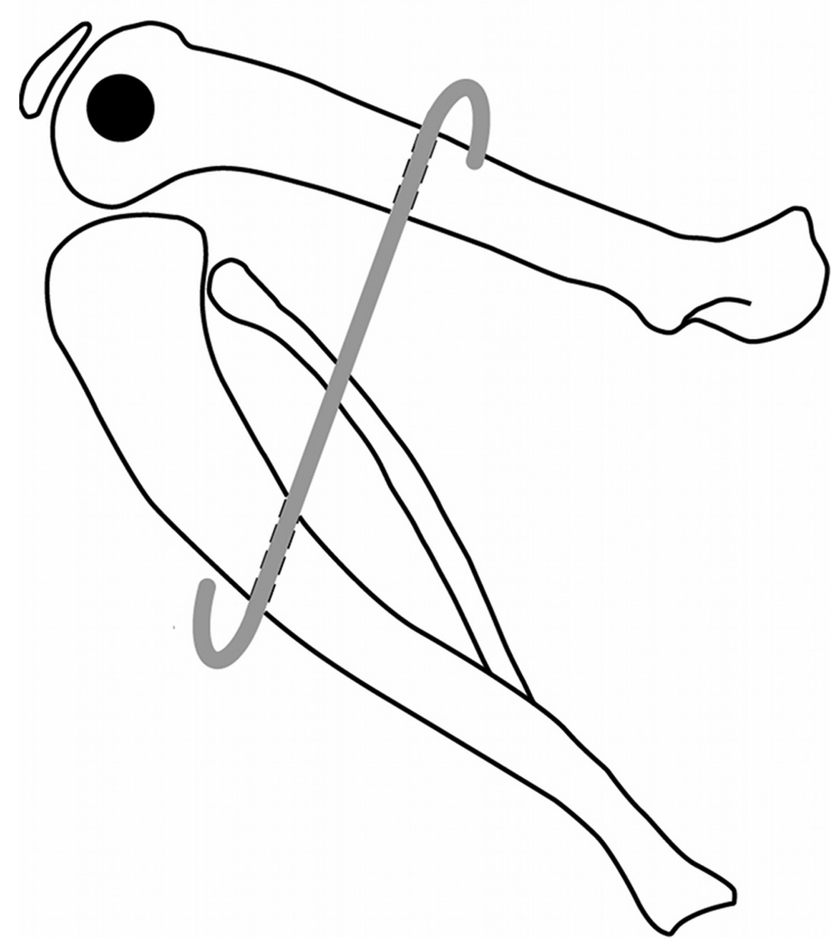

Figure I K-wire fixation and immobilization of a knee joint in a $145^{\circ}$ flexed position. The black spot reflects the hole in the lateral femoral condyle. 
and fixation angle was checked via fluoroscopy. During the 2-week immobilization period, the animals had free cage activity and access to water ad libitum. Drinking water was supplemented with tramadol $(1 \mathrm{mg} / \mathrm{mL}) 3$ days before and 5 days after surgery. Access to food was free after administering the daily dose of the respective drug or placebo. Animals were evaluated at least every second day to identify symptoms of pain or distress and to ensure proper wound healing of the constrained legs. Two weeks after the initial operation, the K-wires were removed and all animals underwent joint angle measurements immediately. All animals were sacrificed after joint angle measurements using carbon dioxide $\left(\mathrm{CO}_{2}\right)$ inhalation. Knee joints were preserved for histological and immunohistochemical examinations.

\section{Joint angle measurements}

The joint contracture angle was defined as the deviation between the physiological extension of the knee joint of each rat before the operation and the remaining degree of extension after 2 weeks of joint immobilization. All angle measurements were performed under general anesthesia after $\mathrm{K}$-wire removal. The rats were placed on a custom-built mechanical testing system and $35 \mathrm{~N}$ mm extension torque was applied to the lower leg. Lateral radiographs were taken (MX-20 cabinet X-ray system, Faxitron, DOM 2009) and analyzed with ImageJ (Version 1.50e). Additional details regarding the positioning of the animals and measurement of the angles were previously reported. ${ }^{38}$ After that first measurement of the extension of the knee joint, all soft tissues were circumferentially cut $10 \mathrm{~mm}$ proximal and distal to the joint line. The gain in joint extension through that incision was defined as myogenic contracture. The difference between the extension after the soft tissue cut and the initial physiological extension of the knee joint was interpreted as arthrogenic or capsular contracture.

\section{Histological assessment}

\section{Tissue preparation}

For histological analysis and morphometrical evaluation, the knee joints were removed and fixed in $4.5 \%$ formaldehyde solution (Carl-Roth, Karlsruhe, Germany) and stored at room temperature after completion of joint angle measurements. The joints were subsequently decalcified in 17.7\% EDTA (Applichem, Darmstadt, Germany) solution buffered with TRIS (Applichem) at room temperature for 6 weeks. Knee joints were embedded in paraffin and cut into $5 \mu \mathrm{m}$ sagittal sections with a microtome. For orientation, every fifth section was stained with HE according to a standard protocol. Slides were chosen from the para-median mid-region of the joint. A slice was considered appropriate when all the relevant structures were present (ie, femoral condyle, tibial plateau, triangular cross section of the posterior part of the meniscus with adjacent posterior joint capsule, untorn synovial folds) and if there were no artifacts from tissue preparation. For the morphometrical evaluation of joint parameters, $n=3$ slides in the control and $n=4$ slides in the losartan and atorvastatin group, respectively, were evaluated independently by two blinded investigators. Cell count and immunohistochemical evaluation were performed by a third blinded investigator with the same number of slices. The samples evaluated all came from different animals. Appropriate slices were processed as follows for immunohistological analysis: hydrated slices were incubated with protein kinase K (Dako, Hamburg, Germany) for $10 \mathrm{mins}$ followed by two 5-min washing steps in PBS. Endogenous peroxidases were blocked with 3\% hydrogen peroxide (Merck, Darmstadt, Germany), followed by several washing steps with PBS, an incubation in $10 \%$ horse serum for 30 mins and incubation with the first antibody overnight at $4^{\circ} \mathrm{C}(\alpha-$ SMA [Arigo Biolaboratories, Hsinchu City, Taiwan] and BSP [Immundiagnostik, Bensheim, Germany]). Controls were incubated in PBS with $1 \%$ BSA. On the next day, the samples were incubated with a biotinylated link (Dako), followed by streptavidinhorseradish peroxidase (HRP, Dako) with several washing steps in between. Incubation and conversion with 3,3'-diaminobenzidine (DAB) substrate-chromogen (Dako) were concurrently stopped with distilled water after the appearance of a brown-colored precipitate in the positive control. Finally, the samples were counterstained with hematoxylin.

\section{Morphometrical evaluation of joint parameters}

Sagittal sections of the knee joints were photographed for histological observation and analyzed with ImageJ (Version 1.50e). Three parameters of the capsule were measured in detail according to a previously reported method: the postero superior synovial length, the posteroinferior synovial length and the capsular thickness behind the posterior border of the meniscus (Figure 2). ${ }^{45,46}$ Knee joint contracture appears to be evoked by a shortened posterior synovial length. ${ }^{47-51}$

\section{Cell count and immunohistochemical evaluation}

Cell nuclei were visualized by counterstaining with hematoxylin; $\alpha$-SMA- and BSP-positive cells were visualized 


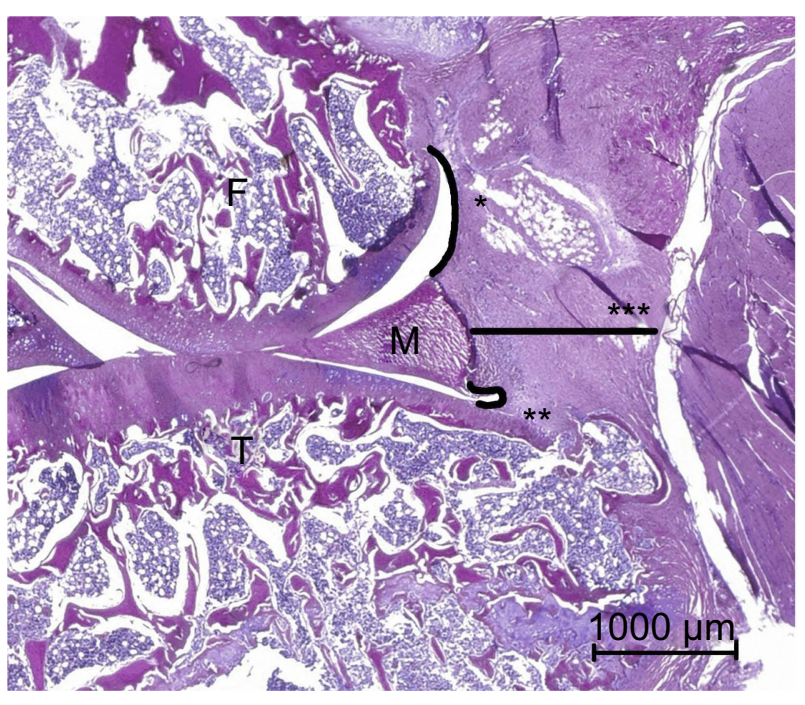

Figure 2 Morphometrical parameters in a HE-stained section in the sagittal plane: *postero superior synovial length between the meniscus and the femur-synovial junction; **posteroinferior synovial length between the meniscus and the tibiasynovial junction; ***capsule thickness between the posterior border of the meniscus and the muscle layer.

Abbreviations: $F$, femoral condyle; T, tibial head; $M$, meniscus.

by immunohistological staining after treatment with the respective antibodies. In brief, an area of 97,035.9 $\mu \mathrm{m}^{2}$ (counting field with side lengths of $361.4 \mu \mathrm{m}$ x $268.5 \mu \mathrm{m}$ ) of the posterior joint capsule, which was located directly behind the meniscus, was chosen for the cell count. This area is referred to as the staining area. For cell count, the images were converted into binary images via a threshold application and counted with ImageJ (Version 1.50e). We have used a cell diameter threshold for cell counting in order not to count small artifacts. The area of the cells was computed and set in relation to the total area Myofibroblasts, pericytic cells and smooth muscle cells of blood vessels express $\alpha$-SMA. ${ }^{7} \alpha$-SMA-positive cells outside of blood vessels were defined as myofibroblasts, whereas all luminal structures with immunostaining of $\alpha$ SMA in their surrounding cells were interpreted as blood vessels. ${ }^{52}$ Since BSP does not only occur in cells, but also in the ECM, a clear differentiation of the cells is not possible as with $\alpha$-SMA. Therefore, for BSP, we only determined the staining intensity and computed the BSPpositive area in relation to the total area. Assessment of staining intensity was performed with ImageJ (Version $1.50 \mathrm{e})$ and measured in folds of intensity in comparison to the blank control.

\section{Statistical analysis}

Statistical analysis was conducted with SPSS V 23.0 (SPSS Inc., Chicago, IL, USA). We conducted a one-way ANOVA with Tukey post-hoc analysis. A Welch-ANOVA with Games-Howell post-hoc analysis was carried out when the assumption of variance homogeneity was violated. Extreme outliers in the data (values above the 95th or below the 5th percentile) were replaced by the 95th or 5th percentile, respectively ( $90 \%$ winsorization). Quantitative results in the text are presented as means $\pm \mathrm{SD}$. Quantitative results in the figures are depicted as a box and whiskers chart. The box represents the IQR and the ends of the whisker represent the respective minimum or maximum value (or, in case of outliers, the ends of the whiskers represent one and a half times the IQR). The median is represented by a horizontal bar in the box. Outliers ( $>1.5$ SDs from the mean) are represented by circles. $p$-values $<0.05$ were considered as statistically significant. The correctness of the applied statistical methods has been verified by the Institute for Medical Biostatistics, Epidemiology and Informatics, University Medical Center Mainz, Germany.

\section{Results}

\section{Perioperative weight development and complications}

All 24 rats that were initially randomized to losartan, atorvastatin and placebo group underwent surgery without any complications. Before the operation, the average weight was $391 \pm 15$ g. Seven rats lost weight during the first week, but all of them recovered during the second week. The mean weight at the time of joint angle measurement was $436 \pm 21 \mathrm{~g}$. We did not see any infections, fractures or K-wire dislocations.

\section{Joint angle measurement Development of joint contracture}

Rats have a physiological deficit of joint extension and do not reach an extension of $0^{\circ}$. At the beginning of the study and before any operation, the rats' physiological extension deficit was $32.4^{\circ} \pm 5.8^{\circ}$ in the losartan group, $32.3^{\circ} \pm 8.8^{\circ}$ in the control and $31.3^{\circ} \pm 8.7^{\circ}$ in the atorvastatin group without significant differences. Joint angle measurements were repeated after 2 weeks, followed by immediate euthanization. After K-wire removal, $35 \mathrm{~N} \mathrm{~mm}$ of extension torque was applied to the ankle and knee joint extension was measured. In this first step, the periarticular muscles were left intact and thus the combined contracture of muscles and joint capsule/ligaments was quantified. We observed a significant increase in joint extension deficit in all groups at week 2 (losartan: $96.1^{\circ} \pm 6.7^{\circ}$, control: $93.1^{\circ}$ 
$\pm 7.8^{\circ}$, atorvastatin: $\left.99.7^{\circ} \pm 12^{\circ}, p<0.001\right)$. However, there was no difference detectable between the groups at week 2 (Figure 3).

\section{Myogenic contracture}

After the first measurement of the joint contracture, the skin was removed and a periarticular myotomy $10 \mathrm{~mm}$ proximal and distal to the joint line was performed. This muscular release led to an improved extension of the knee joint, which corresponded to the extent of joint contracture caused by periarticular muscles. There was no observable significant difference in myogenic contracture between the treatment groups and the control (losartan: $24.8^{\circ} \pm 7.6^{\circ}$ [ $p=0.43$ to control], control: $29.7^{\circ} \pm 5.9^{\circ}$, atorvastatin: $32.9^{\circ} \pm 9.4^{\circ}[p=0.70$ to control $\left.]\right)$. Furthermore, the effect of losartan on myogenic contracture was not different from that of atorvastatin $(p=0.12$, Figure 4$)$.

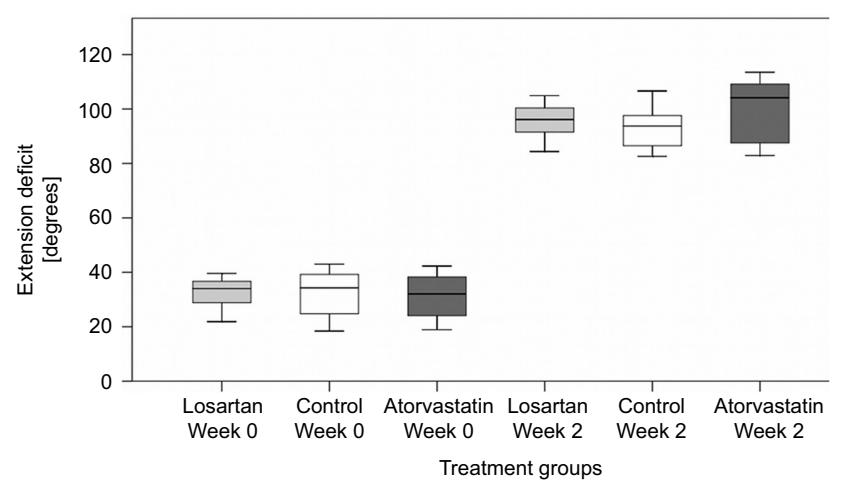

Figure 3 Comparison of the extension deficit of knee joints before treatment and after 2 weeks. Joint contracture (the difference between extension deficit after 2 weeks and week 0 ) developed in all groups without significant differences between the groups.

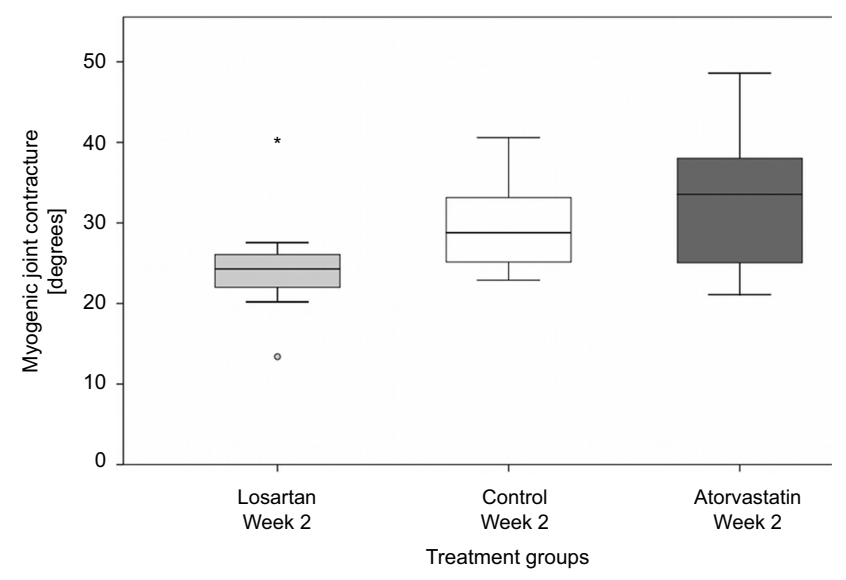

Figure 4 Myogenic joint contracture did not differ significantly between the treatment groups and the control. Outliers are represented by circles and extreme outliers by an asterisk.

\section{Arthrogenic contracture}

A persisting extension deficit after myotomy is caused by joint capsule contracture, ligament shortening and synovial adhesions, summarized as arthrogenic contracture. About half of the total joint contracture can be attributed to arthrogenic contracture. With $31.2^{\circ} \pm 14.0^{\circ}$ in the control, the arthrogenic contracture was not significantly reduced by administration of both losartan $\left(37.2^{\circ} \pm 9.5^{\circ}, p=0.38\right.$ to control $)$ and atorvastatin $\left(31.0^{\circ} \pm 14.7^{\circ}, p=0.99\right.$ to control). As with the results for myogenic contracture, arthrogenic contracture did not vary between both treatment groups ( $p=0.36$, Figure 5).

\section{Histological assessment Joint capsule length}

In absence of structural damage to joint surfaces, arthrogenic contracture is mostly ascribed to a shortened joint capsule and synovial adhesions. Joint tissue sections were harvested after 2 weeks and dyed with H\&E. Digitized and calibrated pictures were used to determine the capsule parameters.

We observed a significantly longer inferior capsule in the losartan group $(2.8 \mathrm{~mm} \pm 1.3 \mathrm{~mm})$ in comparison to the control $(1.1 \pm 0.3 \mathrm{~mm}, p<0.05)$ and to atorvastatin $(0.9 \pm 0.3$ $\mathrm{mm}, p<0.05)$. Atorvastatin did not increase the length of the inferior capsule in comparison to the control $(p=0.74)$. For the superior capsule, we only found a non significant trend toward a longer capsule under medical treatment with both losartan and atorvastatin (losartan: $2.0 \mathrm{~mm}$ $\pm 0.6 \mathrm{~mm}$, control: $1.7 \mathrm{~mm} \pm 1.4 \mathrm{~mm}$, atorvastatin: 1.9 $\mathrm{mm} \pm 1.0 \mathrm{~mm}, p>0.85$, Figure 6).

\section{Joint capsule thickness}

When we compared the two treatment groups, we observed a significant reduction in capsule thickness

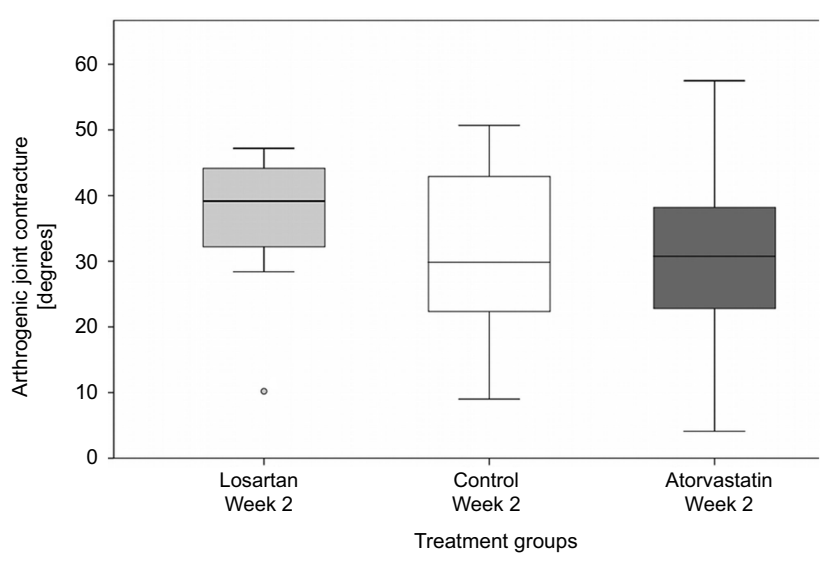

Figure 5 Arthrogenic contracture after administration of losartan, atorvastatin or placebo (control). Outliers are represented by circles. 


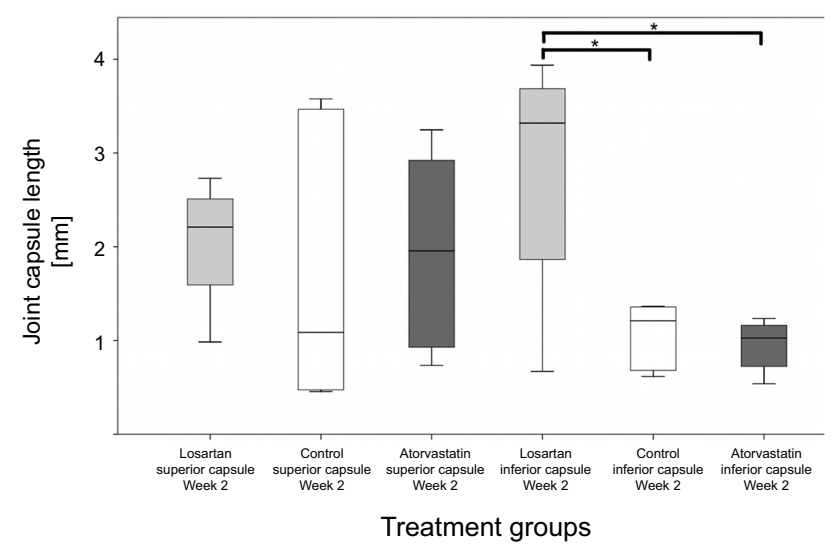

Figure 6 Depiction of the length of the superior and inferior parts of the posterior knee joint capsule after 2 weeks $(* p<0.05)$.

under atorvastatin treatment $(0.7 \mathrm{~mm} \pm 0.2 \mathrm{~mm}, p<0.05$ vs losartan with $1.1 \mathrm{~mm} \pm 0.4 \mathrm{~mm})$. The posterior joint capsule behind the meniscus tended to be thicker when the rats were treated with losartan in comparison to control $(0.8 \mathrm{~mm} \pm 0.3 \mathrm{~mm}, p=0.20)$, while atorvastatin tended to reduce the capsules thickness ( $p=0.50$ to control). However, the differences between treatment groups and the control were not significant at week 2 (Figure 7).

\section{Immunohistochemistry}

Immunohistochemistry of $\alpha$-SMA

Myofibroblasts, pericytic cells and smooth muscle cells of blood vessels in the joint capsule express $\alpha$-SMA. ${ }^{7,53}$ After staining with the respective antibodies, we examined the histological sections. $\alpha$-SMA-positive cells were found in abundance at the transition from the posterior capsule to the meniscus (Figure 8).

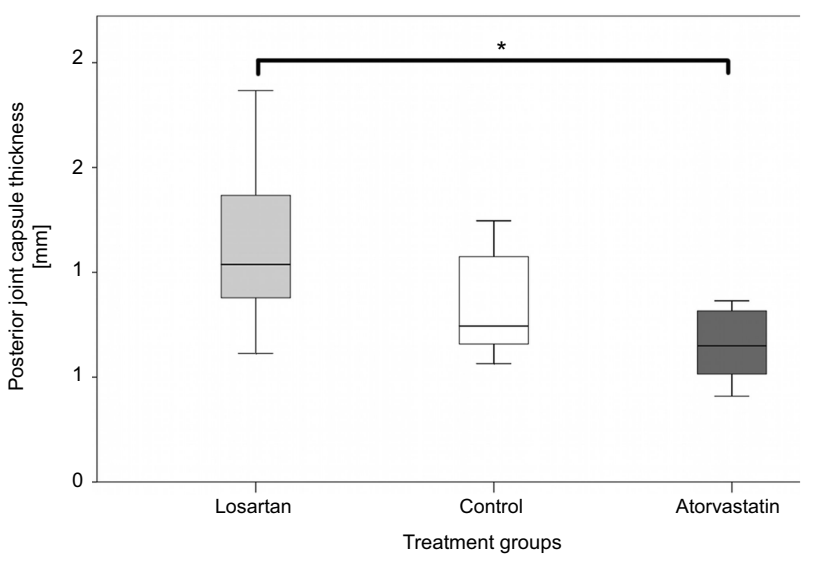

Figure 7 Comparison of the thickness of the posterior knee joint capsule after 2 weeks $(* p 0.05)$.
$\alpha$-SMA-positive cells covered $6.4 \% \pm 4 \%$ of the capsule area in the control. Both losartan and atorvastatin reduced the area covered by $\alpha$-SMA-stained cells $(2.8 \%$ $\pm 1.8 \%[p<0.05]$ and $2.5 \% \pm 1.7 \%[p<0.01]$, respectively). This constellation is also resembled by the absolute and relative number of myofibroblasts. We counted $319 \pm 113$ myofibroblasts, accounting for $79 \%$ of all $406 \pm 157$ cells per counting field in the control. In rats receiving losartan, the myofibroblast numbers decreased to $191 \pm 77$ (61\% of all cells). Atorvastatin lowered the myofibroblast numbers even more to $98 \pm 58$ ( $24 \%$ of all cells, Table 1$)$.

\section{Immunhistochemistry of BSP}

BSP is usually situated in the ECMof bone and plays a role during remodeling of bone and during the formation of ectopic ossifications. ${ }^{54,55}$ BSP was detectable in small amounts in all groups. It was mostly found close to the synovial membrane and in the superficial cartilage areas, as can be seen in the overview image (Figure 9). The assessment of staining intensity showed no major differences between the treatment groups and the control (losartan: $1.3 \pm 0.4$, control: $1.2 \pm 0.8$ and atorvastatin: $1.0 \pm 0.4$ [measured in folds of intensity in comparison to blank control]). Atorvastatin treatment reduced the BSP-stained area by trend $(9.7 \% \pm 9.9 \%)$ in comparison to the control $(19.8 \% \pm 15.6 \%)$ and to losartan $(17.8 \%$ $\pm 10.0 \%$ ).

\section{Discussion}

Joint stiffness is a disabling condition and occurs mostly after trauma or operation. ${ }^{4,56}$ Excessive active exercises or stretching might even aggravate the fibrosis and subsequent motion restriction. ${ }^{57-59}$ Although the surgical treatment of joint stiffness can improve joint motion, there is an urgent need for a non invasive prophylactic or first-line treatment.

In recent years, several new animal models of immobility-induced contractures and PTJS were established (Table 2). Many research groups are interested in understanding the underlying processes of contracture development and how drug application might slow it down or even stop it. After injury of the joint, several different cell types (eg, mast cells, macrophages, neutrophils, platelets, leukocytes and fibroblasts) migrate into the damaged tissue and induce the production of cytokines and growth factors. ${ }^{60,61}$ This leads to excessive collagen production and finally to fibrosis of the joint capsule. ${ }^{62,63}$ Immobilization, local hypoxia and intraarticular hematoma promote the 


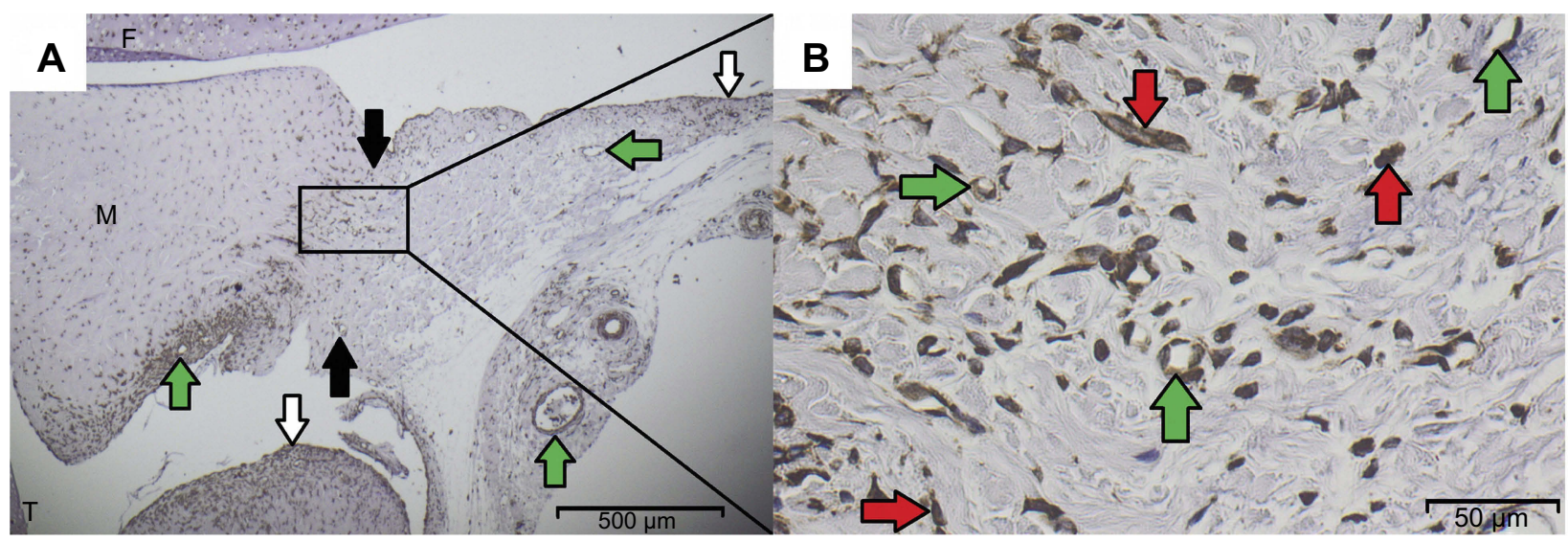

Figure 8 (A) Overview of the histological sagittal section of the posterior knee joint with femur (F), tibia (T), meniscus (M), $\boldsymbol{\alpha S M A - p o s i t i v e ~ v e s s e l s ~ ( g r e e n ~ a r r o w s ) , ~ s u p e r i o r ~}$ and inferior capsular regions (black arrows) and synovial lining (white arrows). (B) Detailed view of the central region behind the meniscus, in which the $36 \mathrm{I} .4 \times 268.5 \mu \mathrm{m}$ counting field was placed. aSMA-positive cells appear brown and either belong to vessels (green arrows) or are defined as myofibroblasts (red arrows).

Table I Total amount and ratio of myofibroblasts

\begin{tabular}{|l|l|l|l|l|}
\hline & Number of myofibroblasts & Total cell number & $\begin{array}{l}\text { Ratio of myofibroblasts/ } \\
\text { total cell number }\end{array}$ & $p$-value \\
\hline Losartan & $191 \pm 77$ & $312 \pm 133$ & $61 \%$ & $\begin{array}{l}p<0.01 \text { vs control } \\
p<0.05 \text { vs atorvastatin }\end{array}$ \\
\hline Control & $319 \pm 113$ & $406 \pm 157$ & $79 \%$ & $\begin{array}{l}p<0.01 \text { vs losartan } \\
p<0.001 \text { vs atorvastatin }\end{array}$ \\
\hline Atorvastatin & $98 \pm 58$ & $410 \pm 108$ & $24 \%$ & $\begin{array}{l}p<0.001 \text { vs control } \\
p<0.05 \text { vs losartan }\end{array}$ \\
\hline
\end{tabular}

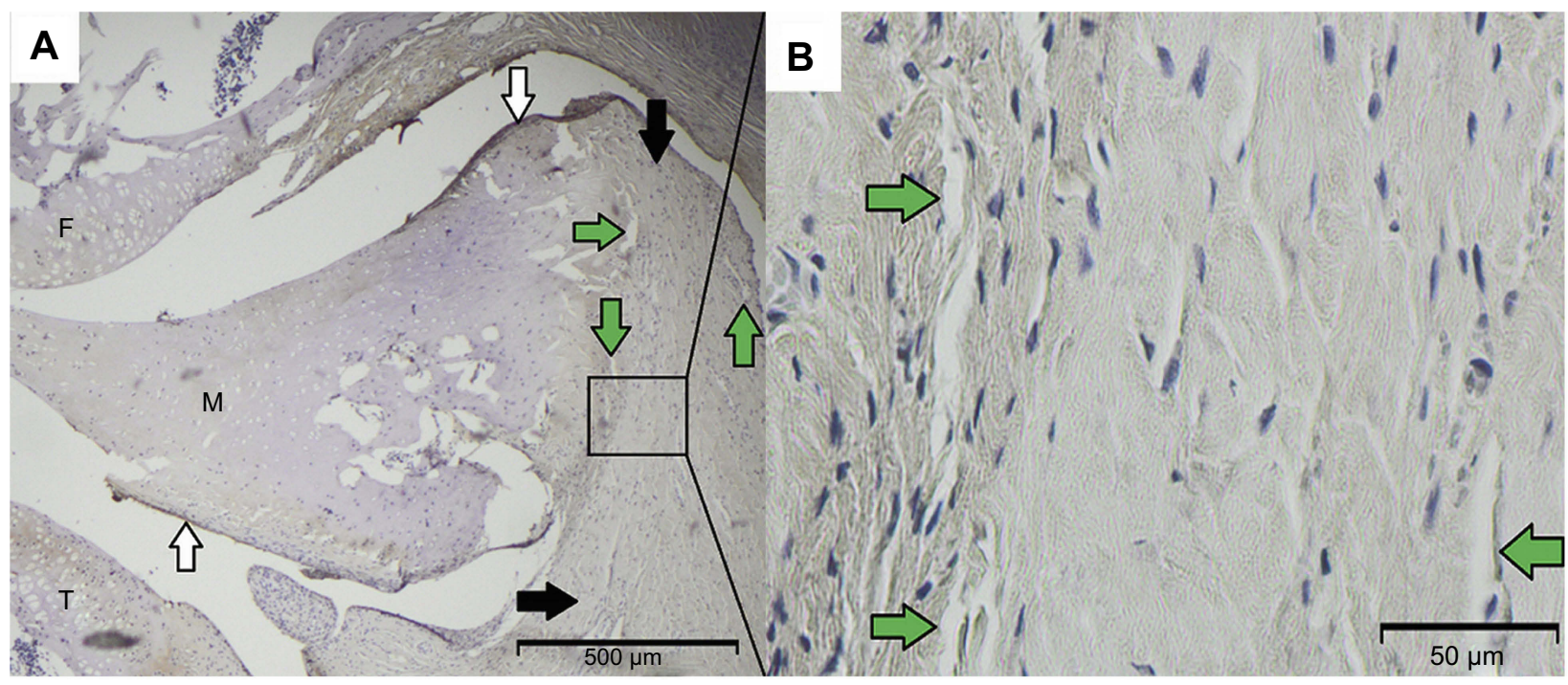

Figure 9 (A) BSP-positive staining is situated mostly in and close to the synovial membrane (white arrows) and in the superficial cartilage of the tibia (T) and the meniscus (M). Superior and inferior capsular regions are pointed out by black arrows. In the enlarged view of the capsule behind the meniscus, (B) BSP-stained areas can be found close to the meniscal border and around vessels (green arrows).

Abbreviation: F, femur.

development of contracture. ${ }^{52,64,65}$ Myofibroblasts play a decisive role in contracture development and fibrotic capsule remodeling by the expression of collagen and the contractile protein $\alpha$-SMA. ${ }^{22,66}$ 


\begin{tabular}{|c|c|c|c|c|c|c|c|c|c|c|c|c|c|c|c|c|c|c|}
\hline 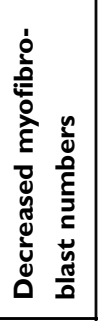 & 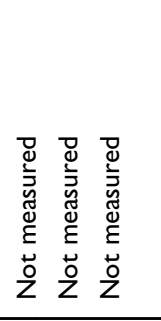 & 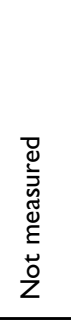 & 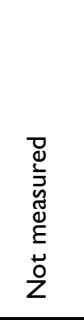 & 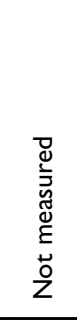 & 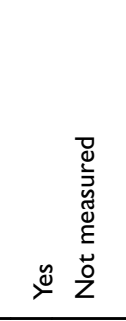 & 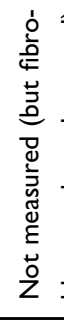 & 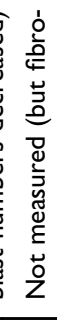 & 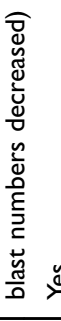 & 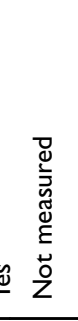 & & 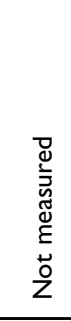 & 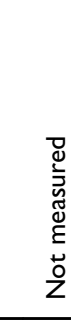 & & 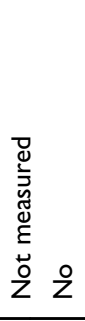 & 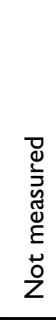 & & 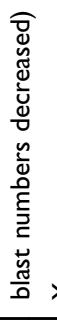 & 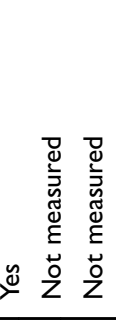 \\
\hline 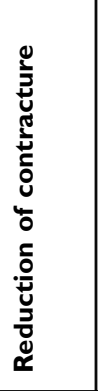 & 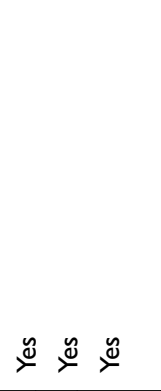 & $\stackrel{\check{\varpi}}{\longleftarrow}$ & $\stackrel{\tilde{\nu}}{\nu}$ & 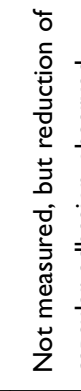 & 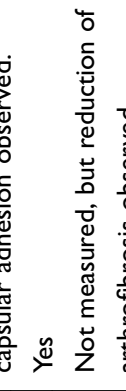 & 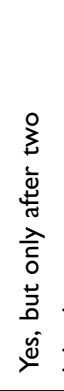 & & & $\check{y}$ & & 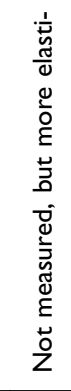 & 更 & & zo z & 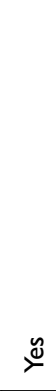 & & & 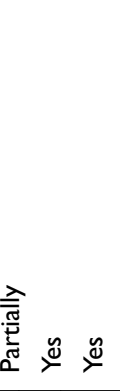 \\
\hline 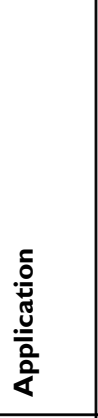 & 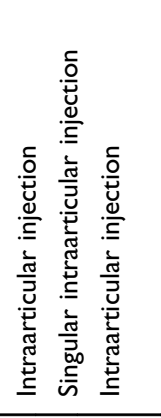 & 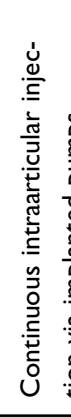 & 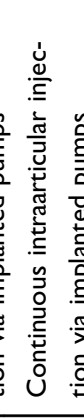 & 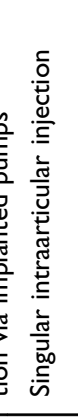 & 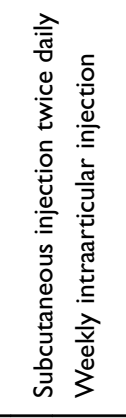 & 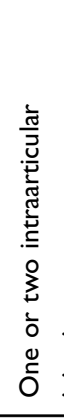 & 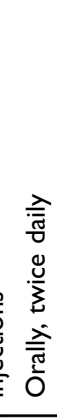 & & 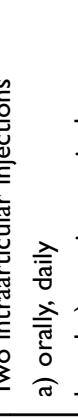 & 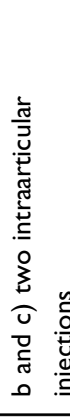 & 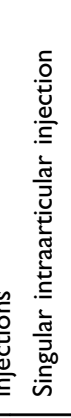 & 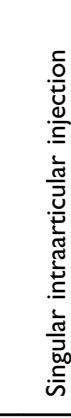 & & 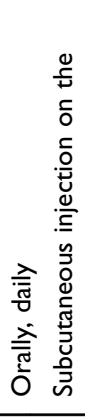 & 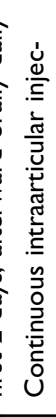 & 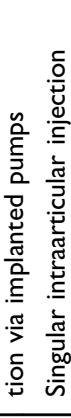 & & 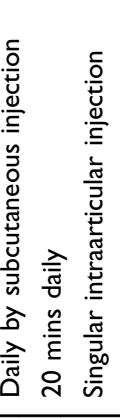 \\
\hline ڤ્o & 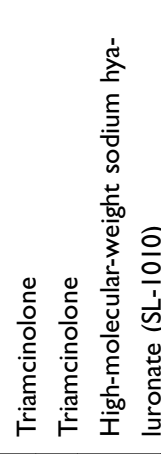 & 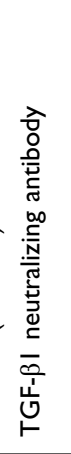 & 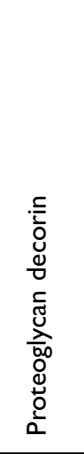 & 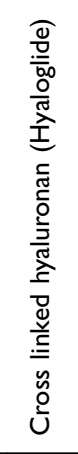 & 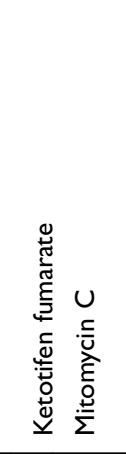 & 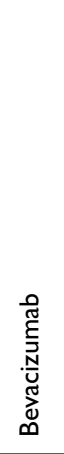 & 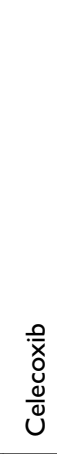 & & 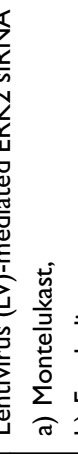 & 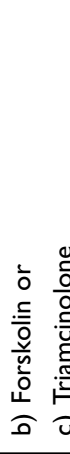 & 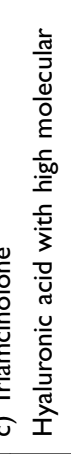 & 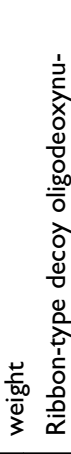 & 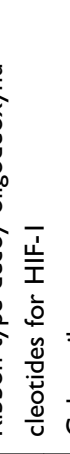 & 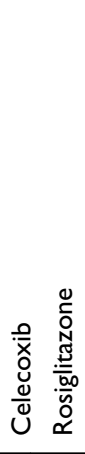 & & 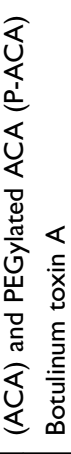 & & 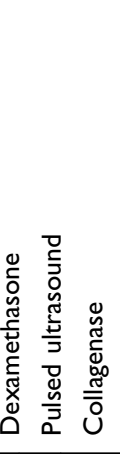 \\
\hline 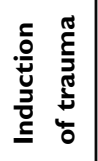 & $\stackrel{\circ}{z} \stackrel{y}{z} \stackrel{\circ}{z}$ & 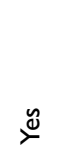 & $\stackrel{\check{\nu}}{\nu}$ & $\stackrel{\varrho}{\check{\nu}}$ & 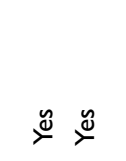 & $\stackrel{\check{\nu}}{\nearrow}$ & 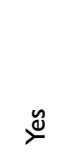 & & & & zo & & & 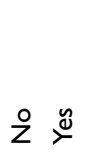 & & $\stackrel{n}{2}$ & & ż ż zo \\
\hline 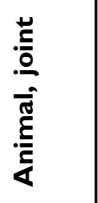 & 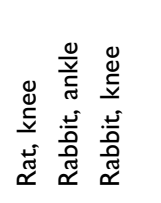 & 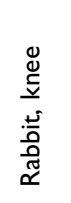 & 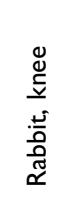 & 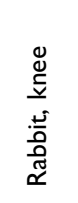 & 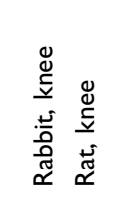 & 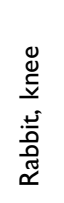 & 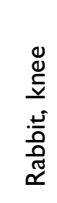 & & 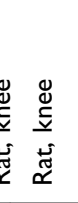 & & 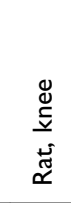 & $\mathscr{\simeq}$ & & 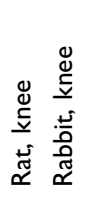 & 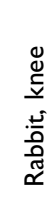 & 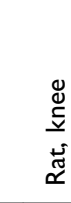 & & 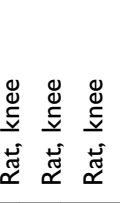 \\
\hline 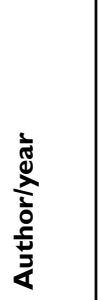 & 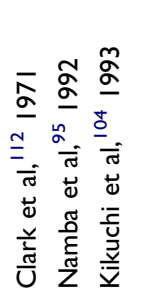 & 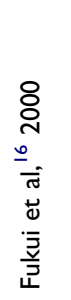 & 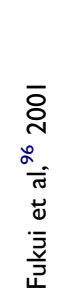 & 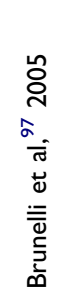 & 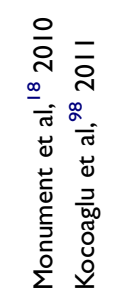 & 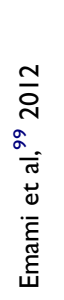 & 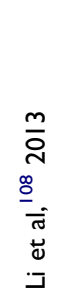 & & 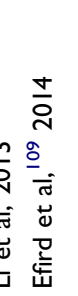 & & 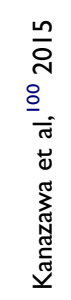 & 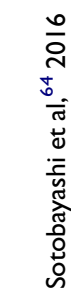 & & 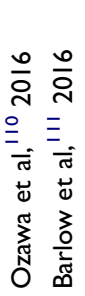 & 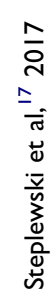 & 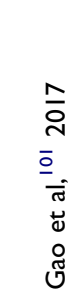 & & 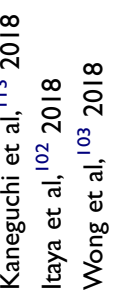 \\
\hline
\end{tabular}


Most of the existing studies focus on anti-inflammatory drugs in order to protect the periarticular connective tissues from posttraumatic or immobility-induced regional inflammation (Table 2). In this blinded and randomized study, we sought to find out, if and how orally administered losartan and atorvastatin affect the early phase (first 2 weeks) of the development of joint contracture. Both drugs have shown to successfully inhibit the TGF- $\beta 1$-triggered inflammatory cascade and subsequent fibrosis in different organ systems, but their effect on the development of joint contracture was unclear. ${ }^{24-27,30-32}$ TGF- $\beta 1$ is involved in the formation of fibrosis in many tissues. ${ }^{67,68}$ It leads to the differentiation of myofibroblasts and increases their synthesis of proteins of the ECM. ${ }^{69}$ In addition, it induces the production of CTGF, which also has a strong fibrotic effect. ${ }^{70}$ By inhibiting matrix metalloproteinases (MMPs), TGF- $\beta 1$ inhibits the degradation of the newly synthesized ECM. ${ }^{71}$ Losartan is an AT1 receptor blocker and prevents direct activation of TGF- $\beta$ as well as the angiotensin IIinduced phosphorylation of Smad2 and Smad3 via the ERK/p38/MAPK pathway. Normally, the phosphorylated Smad2 and Smad3 complex with Smad4 and translocate into the nucleus of the cell. This leads to a transcription of TGF- $\beta$, procollagen I and III and fibronectin. ${ }^{67,72,73}$ Atorvastatin is a 3-hydroxy-3-methylglutaryl coenzyme A (HMG-CoA) reductase inhibitor and is able to inhibit inflammatory responses and collagen fiber production, possibly by inhibiting the expression of TGF- $\beta 1 .^{74}$ Atorvastatin also inhibits the RhoA/ROCK (Rho-associated coiled-coil-containing protein kinase) pathway, which plays an important role in the signal transduction of fibrotic and sclerotic diseases. ${ }^{75-77}$

In the current study, we laid a focus on assessing joint angles, synovial configuration and cell numbers by visualization of myofibroblasts and BSP-positive cells. In a study by Remst et al, a fibrosis of the synovium was found in over $50 \%$ of patients with osteoarthritis (OA), and other studies have found an association between OA and fibrosis as well. ${ }^{78-80}$ There is evidence that high numbers of fibroblasts in knee synovium can prompt inflammation due to overexpression of TGF- $\beta .^{81,82}$ BSP is usually located in the ECM of bone and involved in the primary bone formation during embryonic development. ${ }^{83}$ It could be shown that BSP stimulated osteoblast differentiation, bone growth and vascularization in murine calvarial defect models. ${ }^{84,85}$ Increased levels of BSP are not only reported in the synovial fluid of inflamed knee joints after injury, in rheumatoid arthritis or in early OA, but also in HOs. ${ }^{12,86,87}$ Since HO often occurs in PTJS, it appears that BSP is increasingly expressed during inflammation after trauma and promotes the formation of HO. Yet, the presence and distribution pattern of BSP in the posttraumatic joint is still elusive. In the current study, we created a substantial PTJS after 2 weeks in all groups. BSP was not significantly expressed in the posterior capsule; neither the intensity of antibody staining nor the area coverage of positively stained cells was significantly different between the groups. In our experiments, we could not observe any development of HO 2 weeks after the trauma. It could be that BSP accumulates in the capsule and leads to HO only in a later stage of PTJS and that the time window of 2 weeks in the current study is too narrow to notice a corresponding effect.

Since myofibroblast numbers are increased during the development of a joint contracture and reach a peak level about 2 weeks after trauma in human tissues and animal models, we have chose a period of 2 weeks for our experiment. ${ }^{6,88}$ In our study, the number of myofibroblasts in the posterior joint capsule fell by $40 \%$ in rats receiving treatment with losartan and by nearly $70 \%$ after atorvastatin administration in comparison to the control. Likewise, the area percentage of myofibroblasts was significantly reduced by about $55 \%$ (losartan) and $60 \%$ (atorvastatin), respectively. These findings are in accordance with the observations of Abdel et al, who found the number of myofibroblasts at its peak in the contracted limb 2 weeks after the initial operation in their rabbit model of PTJS. ${ }^{6}$ In immobilization-induced contractures without induced trauma, the limitation to knee range of motion after 2 weeks of immobilization is mostly muscular. ${ }^{47,89}$ This contrasts with observations in our posttraumatic contracture, where the posterior capsule accounted for about half of the total joint contracture (Figures 3 and 4). Morrey et al hypothesize that it may be the combination of soft tissue trauma, instability and bony trauma that leads to a more clinically relevant contracture in humans. ${ }^{90}$ Nesterenko et al found a more severe and permanent contracture in their rabbit model of PTJS after ligamentous and capsular disruption. The combination of capsular contracture, adhesions between bony surfaces and the capsule and intraarticular adhesions could be the reason for the predominance of the arthrogenic component of joint contracture. ${ }^{91}$ However, there are controversial findings from Lake et al, who observed similar histological characteristics for all three groups (ie, sham, minor joint injury and major joint injury) in their rat model of PTJS of the 
elbow. ${ }^{92}$ There are not many in vivo studies on medical treatment of joint stiffness that included the cell count of myofibroblasts (Table 2, right column). In the studies that include myofibroblast or fibroblast count, a concordance between decreasing cell numbers and decreasing contracture could be observed. All these studies consider a longer period than we do in our study, usually between 4 and 8 weeks, in some cases longer. It appears that myofibroblast numbers might not be responsible for the early onset of PTJS, since the drug-induced changes in myofibroblast numbers (Table1) and partially in capsule length (Figure 6) did not translate directly into a significant improvement in range of motion. Accordingly, neither synovial length increased nor synovial thickness decreased after 2 weeks of daily drug application. Scarring at the posterior aspect of the joint after the initial trauma with indirect capsular injury might be responsible for that early arthrogenic joint contracture. It is possible that inhibition of myofibroblasts influences contracture development at a later stage, when the physiological wound healing response is fading and elevated numbers of myofibroblasts result in exuberant fibrotic remodeling. ${ }^{93,94}$

Several working groups have performed experiments on inhibition of joint contracture in rabbits and rats (Table 2). The reservation must be made, however, that the results are hardly comparable due to differences in the research methodology. Around half of the above-mentioned studies concentrate on immobilization-induced contractures and did not induce a trauma to create a PTJS. Although some experimental results suggest that immobilization alone might be adequate to create a stable joint contracture, these models do not fully reproduce the mechanism of PTJS in humans. ${ }^{46,52,89}$ Since there is no comprehensive standard model for the creation of joint stiffness, the various studies differ in several aspects, such as the duration of immobilization, the method of joint contracture measurements, the applied extension torque during the measurements, the distinction between myogenic and arthrogenic factors, the administration of medication and the animal model, to name but a few.

In the existing studies on medical inhibition of the development of joint contracture (Table 2), an improvement of the range of motion could be achieved mostly after intraarticular application of the respective active agents. $^{16,17,64,95-104}$ Although these results constitute an opportunity for the development of a medical treatment of patients with PTJS, the intraarticular application is unfavorable for a number of reasons: i) it is a painful and invasive procedure for the patient, ii) it bears the risk of septic arthritis, iii) it might damage the articular cartilage by chondrotoxic effects or iv) weaken the capsule and ligaments of the knee. ${ }^{105-107}$ Based on the rabbit models of PTJS of Hildebrand et al and Nesterenko et al, our group established a rat model of PTJS of the knee joint that included a rupture of the posterior joint capsule, a hemarthrosis, an intraarticular bone damage and a temporary fixation of the joint. ${ }^{38,65,91}$ In order to avoid the potential risks of intraarticular injections, which might lessen their applicability and acceptance in the treatment of patients, we administered the drugs orally.

There are only two published animal experiments that focus on oral drug administration in PTJS. ${ }^{108,109}$ In the study of Efird et al, montelukast significantly improved joint motion of rats' knee joints 2 weeks after scraping the soft tissues on the medial and lateral condyles and the cartilage of the trochlea. This massive structural damage to the joint might have led to extensive scarring and inflammation, which might explain the effect on joint contracture of the leukotriene receptor antagonist montelukast. In comparison, we sought to prevent structural damage to the cartilage joint surfaces by setting an extracartilaginous bony lesion to be able to examine the capsular contracture only and rule out impairment on joint motion based on an incongruence of the joint partners. Myofibroblast numbers and synovial length were not measured in the study of Efird et al. In the study of Li et al, celecoxib improved joint motion significantly, but myofibroblast numbers and synovial length were not measured. In the following two studies by Ozawa et al and Barlow et al. the drugs were also administered orally. However, they differ from the two studies mentioned above by Efird et al and $\mathrm{Li}$ et al, since Ozawa et al used a non traumatic rat model, whereas Barlow et al initially performed an intra articular injection before switching to oral administration. Ozawa et al measured the synovial length in their non traumatic rat model of knee joint contracture under oral celecoxib treatment after 3 weeks and did neither observe an inhibition of the shortening of the joint capsule nor a reduction of the joint contracture. ${ }^{110}$ Barlow et al administered rosiglitazone subcutaneously during the first 2 days and then switched to oral drug administration in their rabbit model of PTJS, but did not observe an effect on joint contracture development. ${ }^{111}$

There are some limitations to our study that need to be mentioned. First, the manual application of the extension torque using a spring scale might add a human error factor. 
Second, the medication was not administered in different concentrations and serum and joint concentrations of the drugs were not measured. Third, the initial trauma is not really standardized, because hyperextension of the knee joint and drilling of the femoral defect are individual procedures, which might as well lead to bias. Fourth, the immobilization model (ie, using an internal K-wire for joint fixation) does not exactly reflect the human situation and a cast or external fixation might be more suitable. Fifth, the small number of animals in each group might add to the observed variability in the data and mask significant differences. Sixth, immunohistochemistry was limited to myofibroblasts only. Finally, repetitive measurement of the joints is needed to distinguish between muscular and capsular components of the contracture, but might weaken the involved joint structures and lead to larger angles.

\section{Conclusion}

In our placebo-controlled, randomized and blinded experimental study with 24 rats, we examined the effects of the anti fibrotic drugs losartan and atorvastatin on the development of early PTJS. Both losartan and atorvastatin reduced the area covered by $\alpha$-SMA-stained cells (myofibroblasts) and the number of myofibroblasts in the joint capsule 2 weeks after trauma. Losartan increased the length of the inferior joint capsule, but not of the superior capsule and had no effect on capsule thickness. Atorvastatin had no significant influence on capsule length and thickness in comparison to the control. Despite some effects on myofibroblast count and joint capsule, both drugs did not decrease myogenic and arthrogenic joint contracture. BSP was not significantly expressed in the posterior capsule; neither the intensity of antibody staining nor the area coverage of positively stained cells was significantly affected by drug administration. In our future studies, we plan to analyze if this early reduction of myofibroblast numbers affects the long-term contracture development after 4 and more weeks and how atorvastatin and losartan influence gene expression patterns in the posterior knee joint capsule.

\section{Ethics approval}

This study was approved by the local ethics committee "Landesuntersuchungsamt Rheinland-Pfalz" (ID 23 177-07/ G 13-1-043). We have followed the German "Legal ordinance on the Protection of Animals Used for Experimental Purposes or for Other Scientific Purposes (Experimental Animal Welfare Regulation - TierSchVersV)" (https://www. gesetze-im-internet.de/tierschversv/BJNR312600013.html).

\section{Data availability}

The datasets used and/or analyzed during the current study are available from the corresponding author on reasonable request.

\section{Abbreviations list}

$\alpha$-SMA, alpha smooth muscle actin; ACA, anti- $\alpha 2 \mathrm{Ct}$ antibody; AT-1, angiotensin type 1; BSP, bone sialoprotein; $\mathrm{CO}_{2}$, carbon dioxide; CTGF, connective tissue growth factor; DAB, 3,3'-diaminobenzidine; ECM, extracellular matrix; HIF-1, hypoxia-inducible factor 1; HMG-CoA, 3hydroxy-3-methyl-glutaryl-coenzyme A; HO, heterotopic ossification; HRP, horseradish peroxidase; K-wire, Kirschner wire; MMP, matrix metalloproteinases; mRNA, messenger ribonucleic acid; P-ACA, PEGylated anti- $\alpha 2 \mathrm{Ct}$ antibody; PTJS, posttraumatic joint stiffness; ROCK, Rhoassociated coiled-coil-containing protein kinase; TRIS, tris (hydroxymethyl)aminomethane.

\section{Acknowledgments}

The authors extend special thanks to Angelika Ackermann for technical support and Anke Grünow for graphic illustrations. We thank Dr Irene Schmidtmann from the Institute for Medical Biostatistics, Epidemiology and Informatics (IMBEI) for statistical consulting. Our research was funded in 2015 from the Johannes Gutenberg-University Mainz within the "Inneruniversitäre Forschungsförderung Stufe I" program and in 2016 from the German Society of Shoulder and Elbow Surgery (DVSE). The work was performed at the "Molekulares Forschungszentrum operativer Fächer (MFO)" of the University Medical Center Mainz.

\section{Author contributions}

All authors made substantial contributions to conception and design, acquisition of data, or analysis and interpretation of data; took part in drafting the article or revising it critically for important intellectual content; gave final approval of the version to be published; and agree to be accountable for all aspects of the work.

\section{Disclosure}

Dr Andreas Baranowski reports grants from the Johannes Gutenberg-University Mainz and the German Society of Shoulder and Elbow Surgery (DVSE), during the conduct of the study. Dr Anja Klein reports grants from the German Society of Shoulder and Elbow Surgery (DVSE) 
and Inneruniversitäre Forschungsförderung Stufe I, during the conduct of the study. The authors report no other conflicts of interest in this work.

\section{References}

1. Hinz B. The myofibroblast: paradigm for a mechanically active cell. $J$ Biomech. 2010;43(1):146-155. doi:10.1016/j.jbiomech.2009.09.020

2. Desmouliere A, Chaponnier C, Gabbiani G. Tissue repair, contraction, and the myofibroblast. Wound Repair Regen. 2005;13(1):712. doi:10.1111/j.1067-1927.2005.130102.x

3. Hildebrand KA, Zhang M, van Snellenberg W, King GJ, Hart DA, Myofibroblast numbers are elevated in human elbow capsules after trauma. Clin Orthop Relat Res. 2004;(419):189-197. doi:10.1097/ 00003086-200402000-00031

4. Mellema JJ, Lindenhovius AL, Jupiter JB. The posttraumatic stiff elbow: an update. Curr Rev Musculoskelet Med. 2016;9(2):190198. doi:10.1007/s12178-016-9336-9

5. Usher KM, Zhu S, Mavropalias G, Carrino JA, Zhao J, Xu J. Pathological mechanisms and therapeutic outlooks for arthrofibrosis. Bone Res. 2019;7:9.

6. Abdel MP, Morrey ME, Barlow JD, et al. Myofibroblast cells are preferentially expressed early in a rabbit model of joint contracture. J Orthop Res. 2012;30(5):713-719. doi:10.1002/jor.21588

7. Darby I, Skalli O, Gabbiani G. Alpha-smooth muscle actin is transiently expressed by myofibroblasts during experimental wound healing. Lab Invest. 1990;63(1):21-29.

8. Hinz B, Dugina V, Ballestrem C, Wehrle-Haller B, Chaponnier C. Alpha-smooth muscle actin is crucial for focal adhesion maturation in myofibroblasts. Mol Biol Cell. 2003;14(6):2508-2519. doi:10.1091/mbc.e02-11-0729

9. Kis K, Liu X, Hagood JS. Myofibroblast differentiation and survival in fibrotic disease. Expert Rev Mol Med. 2011;13:e27. doi:10.1017/S1462399411001967

10. Charalambous CP, Morrey BF. Posttraumatic elbow stiffness. $J$ Bone Joint Surg Am. 2012;94(15):1428-1437. doi:10.2106/JBJS.K.00711

11. Freeman TA, Parvizi J, Dela Valle CJ, Steinbeck MJ. Mast cells and hypoxia drive tissue metaplasia and heterotopic ossification in idiopathic arthrofibrosis after total knee arthroplasty. Fibrogenesis Tissue Repair. 2010;3:17. doi:10.1186/1755-1536-3-17

12. Bosse A, Wuisman P, Jones DB, Schwarz K. Noncollagenous proteins in heterotopic ossification. Immunohistochemical analysis in 15 paraplegies. Acta Orthop Scand. 1993;64(6):634-638.

13. Hegyi L, Gannon FH, Glaser DL, Shore EM, Kaplan FS, Shanahan CM. Stromal cells of fibrodysplasia ossificans progressiva lesions express smooth muscle lineage markers and the osteogenic transcription factor Runx2/Cbfa-1: clues to a vascular origin of heterotopic ossification? J Pathol. 2003;201(1):141-148. doi:10.1002/path.1413

14. Lohmander LS, Saxne T, Heinegard D. Increased concentrations of bone sialoprotein in joint fluid after knee injury. Ann Rheum Dis. 1996;55(9):622-626. doi:10.1136/ard.55.9.622

15. Larsson E, Mussener A, Heinegard D, Klareskog L, Saxne T. Increased serum levels of cartilage oligomeric matrix protein and bone sialoprotein in rats with collagen arthritis. $\mathrm{Br} J$ Rheumatol. 1997;36(12):1258-1261.

16. Fukui N, Tashiro T, Hiraoka H, Oda H, Nakamura K. Adhesion formation can be reduced by the suppression of transforming growth factor-betal activity. J Orthop Res. 2000;18(2):212-219. doi:10.1002/jor.1100180208

17. Steplewski A, Fertala J, Beredjiklian PK, et al. Blocking collagen fibril formation in injured knees reduces flexion contracture in a rabbit model. J Orthop Res. 2017;35(5):1038-1046. doi:10.1002/ jor.23369
18. Monument MJ, Hart DA, Befus AD, Salo PT, Zhang M, Hildebrand KA. The mast cell stabilizer ketotifen fumarate lessens contracture severity and myofibroblast hyperplasia: a study of a rabbit model of posttraumatic joint contractures. J Bone Joint Surg Am. 2010;92(6):1468-1477. doi:10.2106/JBJS.I.00684

19. Li F, Liu S, Fan C. Lentivirus-mediated ERK2 siRNA reduces joint capsule fibrosis in a rat model of post-traumatic joint contracture. Int $J$ Mol Sci. 2013;14(10):20833-20844. doi:10.3390/ijms141020833

20. Mattyasovszky SG, Hofmann A, Brochhausen C, et al. The effect of the pro-inflammatory cytokine tumor necrosis factor-alpha on human joint capsule myofibroblasts. Arthritis Res Ther. 2010;12(1): R4. doi: $10.1186 /$ ar2902

21. Kulkarni AA, Thatcher TH, Olsen KC, Maggirwar SB, Phipps RP, Sime PJ. PPAR-gamma ligands repress TGFbeta-induced myofibroblast differentiation by targeting the PI3K/Akt pathway: implications for therapy of fibrosis. PLoS One. 2011;6(1):e15909. doi:10.1371/journal.pone.0015909

22. Hinz B, Phan SH, Thannickal VJ, et al. Recent developments in myofibroblast biology: paradigms for connective tissue remodeling. Am J Pathol. 2012;180(4):1340-1355. doi:10.1016/j.ajpath.20 12.02.004

23. Leask A. Potential therapeutic targets for cardiac fibrosis: tGFbeta, angiotensin, endothelin, CCN2, and PDGF, partners in fibroblast activation. Circ Res. 2010;106(11):1675-1680. doi:10.1161/ CIRCRESAHA. 110.217737

24. Klein S, Klösel J, Schierwagen R, et al. Atorvastatin inhibits proliferation and apoptosis, but induces senescence in hepatic myofibroblasts and thereby attenuates hepatic fibrosis in rats. Lab Invest. 2012;92(10):1440-1450. doi:10.1038/labinvest.20 12.106

25. Trebicka J, Hennenberg M, Odenthal M, et al. Atorvastatin attenuates hepatic fibrosis in rats after bile duct ligation via decreased turnover of hepatic stellate cells. J Hepatol. 2010;53(4):702-712. doi:10.1016/j.jhep.2010.04.025

26. Geng J, Zhao Z, Kang W, Wang W, Zhang Y, Zhiming GE. Atorvastatin reverses cardiac remodeling possibly through regulation of protein kinase $\mathrm{D} /$ myocyte enhancer factor $2 \mathrm{D}$ activation in spontaneously hypertensive rats. Pharmacol Res. 2010;61(1):4047. doi:10.1016/j.phrs.2009.08.004

27. Jiang BH, Tardif JC, Sauvageau S, et al. Beneficial effects of atorvastatin on lung structural remodeling and function in ischemic heart failure. J Card Fail. 2010;16(8):679-688. doi:10.1016/j. cardfail.2010.03.003

28. Kane CJ, Hebda PA, Mansbridge JN, Hanawalt PC. Direct evidence for spatial and temporal regulation of transforming growth factor beta 1 expression during cutaneous wound healing. $J$ Cell Physiol. 1991;148(1):157-173. doi:10.1002/jcp.104 1480119

29. Campbell SE, Katwa LC. Angiotensin II stimulated expression of transforming growth factor-beta1 in cardiac fibroblasts and myofibroblasts. J Mol Cell Cardiol. 1997;29(7):1947-1958. doi:10.1006/ jmcc.1997.0435

30. Shibasaki Y, Nishiue T, Masaki H, et al. Impact of the angiotensin II receptor antagonist, losartan, on myocardial fibrosis in patients with end-stage renal disease: assessment by ultrasonic integrated backscatter and biochemical markers. Hypertens Res. 2005;28 (10):787-795. doi:10.1291/hypres.28.787

31. De Mello WC, Specht P. Chronic blockade of angiotensin II AT1receptors increased cell-to-cell communication, reduced fibrosis and improved impulse propagation in the failing heart. $J$ Renin Angiotensin Aldosterone Syst. 2006;7(4):201-205. doi:10.3317/ jraas. 2006.038

32. Yoshiji H, Kuriyama S, Yoshii J, et al. Angiotensin-II type 1 receptor interaction is a major regulator for liver fibrosis development in rats. Hepatology. 2001;34(4 Pt 1):745-750. doi:10.1053/ jhep.2001.28231 
33. Ishidoya S, Morrissey J, McCracken R, Reyes A, Klahr S. Angiotensin II receptor antagonist ameliorates renal tubulointerstitial fibrosis caused by unilateral ureteral obstruction. Kidney Int. 1995;47(5):1285-1294.

34. Molteni A, Moulder JE, Cohen EF, et al. Control of radiationinduced pneumopathy and lung fibrosis by angiotensin-converting enzyme inhibitors and an angiotensin II type 1 receptor blocker. Int $J$ Radiat Biol. 2000;76(4):523-532.

35. Bedair HS, Karthikeyan T, Quintero A, Li Y, Huard J. Angiotensin II receptor blockade administered after injury improves muscle regeneration and decreases fibrosis in normal skeletal muscle. Am J Sports Med. 2008;36(8):1548-1554. doi:10.1177/0363546508315470

36. Cabello-Verrugio C, Morales MG, Cabrera D, Vio CP, Brandan E. Angiotensin II receptor type 1 blockade decreases CTGF/CCN2mediated damage and fibrosis in normal and dystrophic skeletal muscles. J Cell Mol Med. 2012;16(4):752-764. doi:10.1111/j.15824934.2011.01354.x

37. Burks TN, Andres-Mateos E, Marx R, et al. Losartan restores skeletal muscle remodeling and protects against disuse atrophy in sarcopenia. Sci Transl Med. 2011;3(82):82ra37. doi:10.1126/scitranslmed.3002227

38. Baranowski A, Schlemmer L, Forster K, et al. A novel rat model of stable posttraumatic joint stiffness of the knee. J Orthop Surg Res. 2018;13(1):185. doi:10.1186/s13018-018-1026-4

39. Trebicka J, Hennenberg M, Laleman W, et al. Atorvastatin lowers portal pressure in cirrhotic rats by inhibition of RhoA/Rho-kinase and activation of endothelial nitric oxide synthase. Hepatology. 2007;46(1):242-253. doi:10.1002/hep.21673

40. Black AE, Hayes RN, Roth BD, Woo P, Woolf TF. Metabolism and excretion of atorvastatin in rats and dogs. Drug Metab Dispos. 1999;27(8):916-923.

41. Wassmann S, Laufs U, Baumer AT, et al. HMG-CoA reductase inhibitors improve endothelial dysfunction in normocholesterolemic hypertension via reduced production of reactive oxygen species. Hypertension. 2001;37(6):1450-1457.

42. Heller J, Shiozawa T, Trebicka J, et al. Acute haemodynamic effects of losartan in anaesthetized cirrhotic rats. Eur J Clin Invest. 2003;33(11):1006-1012.

43. Kaneko K, Susic D, Nunez E, Frohlich ED. Losartan reduces cardiac mass and improves coronary flow reserve in the spontaneously hypertensive rat. J Hypertens. 1996;14(5):645-653.

44. Gohlke P, Linz W, Scholkens BA, Wiemer G, Unger T. Cardiac and vascular effects of long-term losartan treatment in stroke-prone spontaneously hypertensive rats. Hypertension. 1996;28(3):397-402.

45. Ando A, Hagiwara Y, Onoda Y, et al. Distribution of type A and B synoviocytes in the adhesive and shortened synovial membrane during immobilization of the knee joint in rats. Tohoku $J \operatorname{Exp}$ Med. 2010;221(2):161-168.

46. Ando A, Suda H, Hagiwara Y, Onoda Y, Chimoto E, Itoi E. Remobilization does not restore immobilization-induced adhesion of capsule and restricted joint motion in rat knee joints. Tohoku $J$ Exp Med. 2012;227(1):13-22.

47. Trudel G, Uhthoff HK. Contractures secondary to immobility: is the restriction articular or muscular? An experimental longitudinal study in the rat knee. Arch Phys Med Rehabil. 2000;81(1):6-13.

48. Hagiwara Y, Ando A, Onoda Y, et al. Expression patterns of collagen types I and III in the capsule of a rat knee contracture model. J Orthop Res. 2010;28(3):315-321. doi:10.1002/jor.20997

49. Hagiwara Y, Saijo Y, Chimoto E, et al. Increased elasticity of capsule after immobilization in a rat knee experimental model assessed by scanning acoustic microscopy. Ups J Med Sci. 2006;111(3):303-313. doi:10.3109/2000-1967-054

50. Moriyama H, Yoshimura O, Kawamata S, Takemoto H, Saka Y, Tobimatsu Y. Alteration of knee joint connective tissues during contracture formation in spastic rats after an experimentally induced spinal cord injury. Connect Tissue Res. 2007;48(4):180187. doi:10.1080/03008200701413512
51. Lee S, Sakurai T, Ohsako M, Saura R, Hatta H, Atomi Y. Tissue stiffness induced by prolonged immobilization of the rat knee joint and relevance of AGEs (pentosidine). Connect Tissue Res. 2010;51 (6):467-477. doi:10.3109/03008201003686941

52. Onoda Y, Hagiwara Y, Ando A, et al. Joint haemorrhage partly accelerated immobilization-induced synovial adhesions and capsular shortening in rats. Knee Surg Sports Traumatol Arthrosc. 2014;22(11):2874-2883. doi:10.1007/s00167-013-2659-9

53. Azuma K, Ichimura K, Mita T, et al. Presence of alpha-smooth muscle actin-positive endothelial cells in the luminal surface of adult aorta. Biochem Biophys Res Commun. 2009;380(3):620-626. doi:10.1016/j.bbrc.2009.01.135

54. Bouleftour W, Juignet L, Bouet G, et al. The role of the SIBLING, Bone Sialoprotein in skeletal biology - Contribution of mouse experimental genetics. Matrix Biol. 2016;52-54:60-77. doi:10.1016/j.matbio.2015.12.011

55. Kaden JJ, Bickelhaupt S, Grobholz R, et al. Expression of bone sialoprotein and bone morphogenetic protein-2 in calcific aortic stenosis. J Heart Valve Dis. 2004;13(4):560-566.

56. Frontera WR, Silver JK, Rizzo TD. Essentials of Physical Medicine and Rehabilitation: Musculoskeletal Disorders, Pain, and Rehabilitation. Oxford: Elsevier Health Sciences; 2018.

57. Moseley AM, Herbert RD, Nightingale EJ, et al. Passive stretching does not enhance outcomes in patients with plantarflexion contracture after cast immobilization for ankle fracture: a randomized controlled trial. Arch Phys Med Rehabil. 2005;86(6):1118-1126. doi:10.1016/j.apmr.2004.11.017

58. Kaneguchi A, Ozawa J, Kawamata S, Yamaoka K. Development of arthrogenic joint contracture as a result of pathological changes in remobilized rat knees. J Orthop Res. 2017;35(7):1414-1423. doi:10.1002/jor.23419

59. Kaneguchi A, Ozawa J, Minamimoto K, Yamaoka K. Active exercise on immobilization-induced contractured rat knees develops arthrogenic joint contracture with pathological changes. $J$ Appl Physiol (1985). 2018;124(2):291-301. doi:10.1152/ japplphysiol.00438.2017

60. Morrey ME, Abdel MP, Riester SM, et al. Molecular landscape of arthrofibrosis: microarray and bioinformatic analysis of the temporal expression of 380 genes during contracture genesis. Gene. 2017;610:15-23. doi:10.1016/j.gene.2017.01.025

61. Kumar V, Abbas AK, Fausto N, Robbins SL, Cotran RS. Robbins and Cotran Pathologic Basis of Disease. 7th ed. Philadelphia: Elsevier Saunders; 2005:xv, 1525 p.

62. Monument MJ, Hart DA, Salo PT, Befus AD, Hildebrand KA. Posttraumatic elbow contractures: targeting neuroinflammatory fibrogenic mechanisms. J Orthop Sci. 2013;18(6):869-877. doi:10.1007/s00776-013-0447-5

63. Hildebrand KA, Zhang M, Germscheid NM, Wang C, Hart DA. Cellular, matrix, and growth factor components of the joint capsule are modified early in the process of posttraumatic contracture formation in a rabbit model. Acta Orthop. 2008;79(1):116-125. doi:10.1080/17453670710014860

64. Sotobayashi D, Kawahata H, Anada N, Ogihara T, Morishita R, Aoki M. Therapeutic effect of intra-articular injection of ribbon-type decoy oligonucleotides for hypoxia inducible factor-1 on joint contracture in an immobilized knee animal model. J Gene Med. 2016;18(8):180-192. doi:10.1002/jgm.2 891

65. Hildebrand KA, Sutherland C, Zhang M. Rabbit knee model of post-traumatic joint contractures: the long-term natural history of motion loss and myofibroblasts. J Orthop Res. 2004;22(2):313320. doi:10.1016/j.orthres.2003.08.012

66. Kendall RT, Feghali-Bostwick CA. Fibroblasts in fibrosis: novel roles and mediators. Front Pharmacol. 2014;5:123. doi:10.3389/ fphar.2014.00123 
67. Dobaczewski M, Chen W, Frangogiannis NG. Transforming growth factor (TGF)-beta signaling in cardiac remodeling. J Mol Cell Cardiol. 2011;51(4):600-606. doi:10.1016/j.yjmcc.2010.10.033

68. Biernacka A, Dobaczewski M, Frangogiannis NG. TGF-beta signaling in fibrosis. Growth Factors. 2011;29(5):196-202. doi:10.3109/08977194.2011.595714

69. Desmouliere A, Geinoz A, Gabbiani F, Gabbiani G. Transforming growth factor-beta 1 induces alpha-smooth muscle actin expression in granulation tissue myofibroblasts and in quiescent and growing cultured fibroblasts. J Cell Biol. 1993;122(1):103-111. doi:10.1083/ jcb.122.1.103

70. Ruperez M, Lorenzo O, Blanco-Colio LM, Esteban V, Egido J, Ruiz-Ortega M. Connective tissue growth factor is a mediator of angiotensin II-induced fibrosis. Circulation. 2003;108(12):14991505. doi:10.1161/01.CIR.0000089129.51288.BA

71. Mauviel A. Transforming growth factor-beta: a key mediator of fibrosis. Methods Mol Med. 2005;117:69-80. doi:10.1385/1-59259940-0:069

72. Schultz Jel J, Witt SA, Glascock BJ, et al. TGF-beta1 mediates the hypertrophic cardiomyocyte growth induced by angiotensin II. $J$ Clin Invest. 2002;109(6):787-796. doi:10.1172/JCI14190

73. Sun Y, Zhang J, Zhang JQ, Ramires FJ. Local angiotensin II and transforming growth factor-betal in renal fibrosis of rats. Hypertension. 2000;35(5):1078-1084.

74. Arnaud C, Braunersreuther V, Mach F. Toward immunomodulatory and anti-inflammatory properties of statins. Trends Cardiovasc Med. 2005;15(6):202-206. doi:10.1016/j.tcm.2005.07.002

75. Peters SL, Michel MC. The RhoA/Rho kinase pathway in the myocardium. Cardiovasc Res. 2007;75(1):3-4. doi:10.1016/j. cardiores.2007.04.016

76. Lin G, Craig GP, Zhang L, et al. Acute inhibition of Rho-kinase improves cardiac contractile function in streptozotocin-diabetic rats. Cardiovasc Res. 2007;75(1):51-58. doi:10.1016/j.cardiores. 2007.03.009

77. Tada S, Iwamoto H, Nakamuta M, et al. A selective ROCK inhibitor, Y27632, prevents dimethylnitrosamine-induced hepatic fibrosis in rats. J Hepatol. 2001;34(4):529-536.

78. Remst DF, Blaney Davidson EN, van der Kraan PM. Unravelling osteoarthritis-related synovial fibrosis: a step closer to solving joint stiffness. Rheumatology (Oxford). 2015;54(11):1954-1963. doi:10. 1093/rheumatology/kev228

79. Oehler S, Neureiter D, Meyer-Scholten C, Aigner T. Subtyping of osteoarthritic synoviopathy. Clin Exp Rheumatol. 2002;20(5):633640.

80. Scanzello CR, Goldring SR. The role of synovitis in osteoarthritis pathogenesis. Bone. 2012;51(2):249-257. doi:10.1016/j.bone.2012. 02.012

81. Snelling SJ, Bas S, Puskas GJ, et al. Presence of IL-17 in synovial fluid identifies a potential inflammatory osteoarthritic phenotype. PLoS One. 2017;12(4):e0175109. doi:10.1371/journal.pone.017 5109

82. Shen J, Li S, Chen D. TGF-beta signaling and the development of osteoarthritis. Bone Res. 2014;2. doi:10.1038/boneres.2 014.2

83. Midura RJ, Wang A, Lovitch D, Law D, Powell K, Gorski JP. Bone acidic glycoprotein-75 delineates the extracellular sites of future bone sialoprotein accumulation and apatite nucleation in osteoblastic cultures. J Biol Chem. 2004;279(24):25464-25473. doi:10.1074/ jbc.M312409200

84. Kruger TE, Miller AH, Wang J. Collagen scaffolds in bone sialoprotein-mediated bone regeneration. Sci World J. 2013;2013:1-6. doi: $10.1155 / 2013 / 812718$

85. Xu L, Anderson AL, Lu Q, Wang J. Role of fibrillar structure of collagenous carrier in bone sialoprotein-mediated matrix mineralization and osteoblast differentiation. Biomaterials. 2007;28 (4):750-761. doi:10.1016/j.biomaterials.2006.09.022
86. Mansson B, Geborek P, Saxne T. Cartilage and bone macromolecules in knee joint synovial fluid in rheumatoid arthritis: relation to development of knee or hip joint destruction. Ann Rheum Dis. 1997;56(2):91-96. doi:10.1136/ard.56.2.91

87. Petersson IF, Boegard T, Svensson B, Heinegard D, Saxne T. Changes in cartilage and bone metabolism identified by serum markers in early osteoarthritis of the knee joint. Br J Rheumatol. 1998;37(1):46-50.

88. Doornberg JN, Bosse T, Cohen MS, Jupiter JB, Ring D, Kloen P. Temporary presence of myofibroblasts in human elbow capsule after trauma. J Bone Joint Surg Am. 2014;96(5):e36. doi:10.2106/ JBJS.M.00453

89. Trudel G, Uhthoff HK, Goudreau L, Laneuville O. Quantitative analysis of the reversibility of knee flexion contractures with time: an experimental study using the rat model. BMC Musculoskelet Disord. 2014;15:338. doi:10.1186/1471-2474-15-338

90. Morrey BF. The posttraumatic stiff elbow. Clin Orthop Relat Res. 2005;431:26-35.

91. Nesterenko S, Morrey ME, Abdel MP, et al. New rabbit knee model of posttraumatic joint contracture: indirect capsular damage induces a severe contracture. J Orthop Res. 2009;27(8):1028-1032. doi:10.1002/jor.20845

92. Lake SP, Castile RM, Borinsky S, Dunham CL, Havlioglu N, Galatz LM. Development and use of an animal model to study post-traumatic stiffness and contracture of the elbow. J Orthop Res. 2016;34(2):354-364. doi:10.1002/jor.22981

93. Ghahary A, Shen YJ, Scott PG, Tredget EE. Expression of fibronectin messenger RNA in hypertrophic and normal dermal tissues and in vitro regulation by interferon alfa- $2 \mathrm{~b}$. Wound Repair Regen. 1993;1(3):166-174. doi:10.1046/j.1524-475X.19 93.10306.x

94. Tredget EE, Nedelec B, Scott PG, Ghahary A. Hypertrophic scars, keloids, and contractures. The cellular and molecular basis for therapy. Surg Clin North Am. 1997;77(3):701-730.

95. Namba RS, Kabo JM, Dorey FJ, Meals RA. Intra-articular corticosteroid reduces joint stiffness after an experimental periarticular fracture. J Hand Surg Am. 1992;17(6):1148-1153.

96. Fukui N, Fukuda A, Kojima K, Nakajima K, Oda H, Nakamura K. Suppression of fibrous adhesion by proteoglycan decorin. $J$ Orthop Res. 2001;19(3):456-462. doi:10.1016/S0736-0266(00) 90016-0

97. Brunelli G, Longinotti C, Bertazzo C, Pavesio A, Pressato D. Adhesion reduction after knee surgery in a rabbit model by Hyaloglide, a hyaluronan derivative gel. J Orthop Res. 2005;23 (6):1377-1382. doi:10.1016/j.orthres.2005.05.001.1100230620

98. Kocaoglu B, Akgun U, Nalbantoglu U, Poyanli O, Karahan M. Adhesion reduction after knee surgery in a rat model by mitomycin C. Knee Surg Sports Traumatol Arthrosc. 2011;19(1):94-98. doi:10.1007/s00167-010-1154-9

99. Emami MJ, Jaberi FM, Azarpira N, Vosoughi AR, Tanideh N. Prevention of arthrofibrosis by monoclonal antibody against vascular endothelial growth factor: a novel use of bevacizumab in rabbits. Orthop Traumatol Surg Res. 2012;98(7):759-764. doi:10.1016/j.otsr.2012.05.020

100. Kanazawa K, Hagiwara Y, Tsuchiya M, et al. Preventing effects of joint contracture by high molecular weight hyaluronan injections in a rat immobilized knee model. Int J Clin Exp Pathol. 2015;8 (4):3426-3440.

101. Gao ZY, Wu JX, Liu WB, Sun JK. Reduction of adhesion formation after knee surgery in a rat model by botulinum toxin A. Biosci Rep. 2017;37:2. doi:10.1042/BSR20160460

102. Itaya N, Yabe Y, Hagiwara Y, et al. Effects of low-intensity pulsed ultrasound for preventing joint stiffness in immobilized knee model in rats. Ultrasound Med Biol. 2018;44(6):1244-1256. doi:10.1016/ j.ultrasmedbio.2018.02.002 
103. Wong K, Trudel G, Laneuville O. Intra-articular collagenase injection increases range of motion in a rat knee flexion contracture model. Drug Des Devel Ther. 2018;12:15-24. doi:10.2147/DDDT. S144602

104. Kikuchi TJJPT. Therapeutic effect of high molecular weight sodium hyaluronate (SL-1010) on the experimental osteoarthritis induced by rabbit knee immobilization. Jpn Pharmac Ther. 1993;21:123-131.

105. Xu C, Peng H, Li R, et al. Risk factors and clinical characteristics of deep knee infection in patients with intra-articular injections: a matched retrospective cohort analysis. Semin Arthritis Rheum. 2018;47(6):911-916. doi:10.1016/j.semarthrit.2017.10.013

106. Wernecke C, Braun HJ, Dragoo JL. The effect of intra-articular corticosteroids on articular cartilage: a systematic review. Orthop J Sports Med. 2015;3(5):2325967115581163. doi:10.1177/23259 67115581163

107. Williams A, Hui J, Tai -C-C. Ligament and Tendon. In: Basic Orthopaedic Sciences. 2nd ed. Milton Park: CRC Press; 2017:143-156.

108. Li F, He B, Liu S, Fan C. Celecoxib effectively inhibits the formation of joint adhesions. Exp Ther Med. 2013;6(6):1507-1511. doi:10.3892/etm.2013.1336
109. Efird W, Kellam P, Yeazell S, Weinhold P, Dahners LE. An evaluation of prophylactic treatments to prevent post traumatic joint stiffness. J Orthop Res. 2014;32(11):1520-1524. doi:10.1002/ jor. 22700

110. Ozawa J, Kaneguchi A, Tanaka R, Kito N, Moriyama H. Cyclooxygenase-2 inhibitor celecoxib attenuates joint contracture following immobilization in rat knees. BMC Musculoskelet Disord. 2016;17(1):446. doi:10.1186/s12891-016-1134-4

111. Barlow JD, Morrey ME, Hartzler RU, et al. Effectiveness of rosiglitazone in reducing flexion contracture in a rabbit model of arthrofibrosis with surgical capsular release: a biomechanical, histological, and genetic analysis. Bone Joint Res. 2016;5 (1):11-17. doi:10.1302/2046-3758.51.2000593

112. Clark DD, Weckesser EC. The influence of triamcinolone acetonide on joint stiffness in the rat. J Bone Joint Surg Am. 1971;53 (7):1409-1414.

113. Kaneguchi A, Ozawa J, Yamaoka K. Anti-inflammatory drug dexamethasone treatment during the remobilization period improves range of motion in a rat knee model of joint contracture. Inflammation. 2018. doi:10.1007/s10753-018-0788-5

\section{Publish your work in this journal}

Drug Design, Development and Therapy is an international, peerreviewed open-access journal that spans the spectrum of drug design and development through to clinical applications. Clinical outcomes, patient safety, and programs for the development and effective, safe, and sustained use of medicines are a feature of the journal, which has also been accepted for indexing on PubMed Central. The manuscript management system is completely online and includes a very quick and fair peer-review system, which is all easy to use. Visit http://www. dovepress.com/testimonials.php to read real quotes from published authors. 